Bangladesh J. Bot. 48(3): 513-520, 2019 (September)

\title{
EFFECTS OF LIGHT STRESS AND LIGHT RECOVERY ON TWO MAIZE (ZEA MAYS L.) CULTIVARS
}

\author{
Hongyu Zhang ${ }^{1}$, Ping Tian, Nan Mei, Pengxiang Sui, Wenke Zhang and Hua Qi \\ Agronomy College, Shenyang Agricultural University, 110866 Shenyang, PR China
}

Keywords: Maize, Weak light stress, Light recovery, Chlorophyll, Photosynthesis

\begin{abstract}
The responses of a density-tolerant (ZD909) and a density-intolerant (DY405) maize cultivar to weak light stress and light recovery were compared. Photosynthetic characteristics and chlorophyll fluorescence parameters were analyzed under three light treatments: natural light (control), 44\% shading and 66\% shading. The light-saturation point and light-compensation point of both the maize cultivars decreased, whereas the apparent quantum efficiency increased during the shade period and the decreasing degree of light-saturation point and light-compensation point and the increasing degree of apparent quantum efficiency of the ZD909 were both higher than those of DY405. The weak light stress in the spike stage had a greater influence on the photosynthetic characteristics and chlorophyll fluorescence parameters of DY405, which indicated DY405 was less able to adapt to a weak light environment compared with ZD909.
\end{abstract}

\section{Introduction}

With the population growth and changes in the environment, the arable land available per capita has gradually reduced and the adverse environmental factors that affect plant growth have increased, challenging food security (Rozendaal et al. 2006, Pires et al. 2011). The shade tolerance of maize is determined by genetic characteristics and external environmental changes which influenced the maize yields (Wang et al. 2009, Liang et al. 2010).

The content of chlorophyll and its fluorescence kinetic parameters can be sensitive to reflect the change of photosynthesis. This parameter is an internal probe to study the relationships between plant photosynthesis and the environment (Lichtenthaler 1988, Olaf and Snel 1990). The influence of weak light stress on maize growth and development has been well documented globally (Bell et al. 2000, Jiang et al. 2002, Zhang et al. 2007). Weak light stress increases the content of chlorophyll a and chlorophyll b but decreases the chlorophyll a/b value (Singh et al. 1988, Viji et al. 1997, Dai et al. 2009,). Shade affects photosynthesis parameters, decreasing the maximum net photosynthetic rate, light-compensation point and dark respiration rate (Feng et al. 2004, Craine and Reich 2005, Joesting et al. 2009, Du et al. 2011, Wang et al. 2015). In wheat, different density-tolerant cultivars had higher chlorophyll content and Fv/Fm under moderate shade compared with a control. In these plants, the content of chlorophyll and $\mathrm{Fv} / \mathrm{Fm}$ decreased and the $\Phi$ PSII increased in high-shade treatments (Praba et al. 2004). Decreases in maximum quantum yield of PSII $(\mathrm{Fv} / \mathrm{Fm})$ have not been observed at any stages of leaf development under low light conditions, but actual PSII efficiency under irradiance $\left(\Phi_{\text {PSII }}\right)$ is lower and accompanied by an increase in non-photochemical quenching (NPQ) (Lv et al. 2012).

It is revealed that, compared to the chlorophyll content, chlorophyll fluorescence parameters and photosynthetic characteristics of two maize cultivars, eg. DY405 and ZD909. DY405 were less able to adapt to a weak light environment as against ZD909 under weak light stress and during a light recovery period. This study provides a theoretical basis for breeding maize with improved photosynthetic ability under typical cultivation conditions.

*Author for correspondence: <qihua10@163.com>. ${ }^{1}$ Farming and Animal Husbandry Bureau of Tongliao, 028005 Inner Mongolia, PR China. 


\section{Materials and Methods}

The field experiment was carried out in Shenyang Agricultural University, China. Two maize cultivars currently used in a local maize production, Zhongdan909 (density-tolerant, ZD909) (Zheng58 $\times$ HD586) and Danyu405 (density-intolerant, DY405) (Dan299 $\times$ DanM9-2) were used.

The top of the maize canopy was covered by layers of black net screens starting from the jointing stage (20 June, 2015) to the tasseling stage (30 July, 2015) to provide shading treatments. The $44 \%$ shading treatment blocked approximately $44 \%$ of the light and the $66 \%$ shading treatment blocked approximately $66 \%$ sun light.

Irradiance was measured with an LP-80 plant canopy digital image analyzer (CID Company, Camas, WA, USA) $50 \mathrm{~cm}$ above the maize canopy. Canopy $\mathrm{CO}_{2}$ concentration, relative humidity and air temperature were measured with a LI-6400XT Portable Photosynthesis System (LI-COR, Inc, Lincoln, NE, USA). Soil temperatures were determined with a geothermometer in the upper $0-5 \mathrm{~cm}$ of soil. All measurements were made daily at 11:00 a.m. for seven consecutive days (4 July, 2015 to 10 July, 2015). Table 1 shows the microclimate data of shading treatments in the experimental plots.

Table 1. Effects of shading treatments on microclimate in experimental plots.

\begin{tabular}{lcccccc}
\hline Cultivar & Treatment & $\begin{array}{c}\text { Light intensity } \\
(\text { lux })\end{array}$ & $\begin{array}{c}\mathrm{CO}_{2} \text { conc. } \\
\left(\mu \mathrm{mol} \cdot \mathrm{mol}^{-1}\right)\end{array}$ & $\begin{array}{c}\text { Relative } \\
\text { humidity } \\
(\%)\end{array}$ & $\begin{array}{c}\text { Air temp. } \\
\left({ }^{\circ} \mathrm{C}\right)\end{array}$ & $\begin{array}{c}5 \mathrm{~cm} \\
\text { underground } \\
\text { temp. }\left({ }^{\circ} \mathrm{C}\right)\end{array}$ \\
\hline ZD909 & No shade & $1767.14 \pm 88.50 \mathrm{a}$ & $368.28 \pm 9.52 \mathrm{a}$ & $36.06 \pm 3.59 \mathrm{a}$ & $37.93 \pm 1.66 \mathrm{a}$ & $23.81 \pm 1.15 \mathrm{a}$ \\
& $44 \%$ shade & $996.71 \pm 39.99 \mathrm{~b}$ & $367.98 \pm 11.06 \mathrm{a}$ & $38.72 \pm 2.81 \mathrm{a}$ & $35.18 \pm 2.17 \mathrm{~b}$ & $23.27 \pm 1.08 \mathrm{~b}$ \\
& $66 \% \quad "$ & $608.29 \pm 46.02 \mathrm{c}$ & $364.13 \pm 11.51 \mathrm{a}$ & $37.62 \pm 3.82 \mathrm{a}$ & $31.25 \pm 2.38 \mathrm{c}$ & $22.47 \pm 1.22 \mathrm{c}$ \\
DY405 & No shade & $1778.57 \pm 117.43 \mathrm{a}$ & $363.51 \pm 10.64 \mathrm{a}$ & $38.06 \pm 3.36 \mathrm{a}$ & $38.10 \pm 1.66 \mathrm{a}$ & $25.79 \pm 1.08 \mathrm{a}$ \\
& $44 \%$ shade & $997.00 \pm 41.74 \mathrm{~b}$ & $365.67 \pm 11.60 \mathrm{a}$ & $38.35 \pm 2.49 \mathrm{a}$ & $34.60 \pm 1.76 \mathrm{~b}$ & $24.21 \pm 0.99 \mathrm{~b}$ \\
& $66 \% \quad "$ & $603.71 \pm 63.29 \mathrm{c}$ & $366.66 \pm 11.20 \mathrm{a}$ & $38.08 \pm 4.55 \mathrm{a}$ & $32.54 \pm 1.57 \mathrm{c}$ & $22.61 \pm 1.32 \mathrm{c}$ \\
\hline
\end{tabular}

Values in a column with different letters are significantly different $(\mathrm{p} \leq 0.05)$.

At 8, 16 and 24 days after starting the shading treatment, and at 8, 16 and 24 days after returning plots to normal light levels, three leaves from each replicated plant were sampled. A $0.1 \mathrm{~g}$ leaf sample was sliced and incubated with $10 \mathrm{ml}$ of an extraction solution containing equal volume of acetone and anhydrous ethanol and stored in dark for $24 \mathrm{hrs}$ before using the colorimetric method to determine leaf chlorophyll content. Chlorophyll content and chlorophyll a/b were analyzed calorimetrically (Arnon 1949).

Chlorophyll fluorescence parameters were measured with a pre-programmed modular chlorophyll fluorescence monitoring system (FMS-2, Hansatech Instruments, Norfolk, UK), under partially cloudy or cloudless conditions. The measurements were taken from leaf lamina avoiding midrib region and major veins from unrolled leaf of penultimate or ear leaf of three randomly selected plants. The $\mathrm{F}_{0}$ (minimum initial fluorescence) and $\mathrm{F}_{\mathrm{m}}$ (maximal fluorescence) of leaves in the dark for 20 min were measured. The $F_{s}$ (steady state fluorescence) and $F_{m}{ }^{\prime}$ were determined under the conditions of actinic light and saturation pulse value, respectively. After the actinic light had been turned off, the $\mathrm{F}_{0}{ }^{\prime}$ value was obtained after the far red light was turned on for $3 \mathrm{sec}$. Leaf chlorophyll fluorescence parameters, $\mathrm{F}_{0}$ (minimum fluorescence), $\mathrm{F}_{\mathrm{v}} / \mathrm{F}_{\mathrm{m}}$ (maximum efficiency of PSII photochemistry under dark-adaption), $\Phi_{\text {PSII }}$ (quantum yield of PSII), and the ETR were calculated (Mu et al. 2010, Li et al. 2007). 
The data were processed with Microsoft Excel 2007 to obtain averages, and standard errors (SE). All data were statistically analyzed using SPSS v. 20.0 (IBM Co. USA), and the mean values of each treatment group were subjected to multiple comparisons analysis using a least squares difference (LSD) test and a significance level of ( $\mathrm{p}<0.05)$. Graphs and light-response curve fitting and related parameter estimation were completed in Origin v. 8.0. All data were means of at least three replicates with standard deviations.

\section{Results and Discussion}

Content of chlorophyll $\mathrm{a}$, chlorophyll $\mathrm{b}$, chlorophyll $\mathrm{a}+\mathrm{b}$, and the value of chlorophyll $\mathrm{a} / \mathrm{b}$ differed in different shading treatments and over time (Fig. 1). Compared with the control, content of chlorophyll a of the density-tolerant cultivar ZD909 increased on the day 6 after shading whereas the density-intolerant cultivar DY405 decreased (Fig. 1a, b). With a greater degree of shading, chlorophyll content in ZD909 increased on day 6 after shading (Fig. 1e, f). Substantial shade can lead to the decline of total chlorophyll content and decreased the ability of plants to adapt to weak light stress.
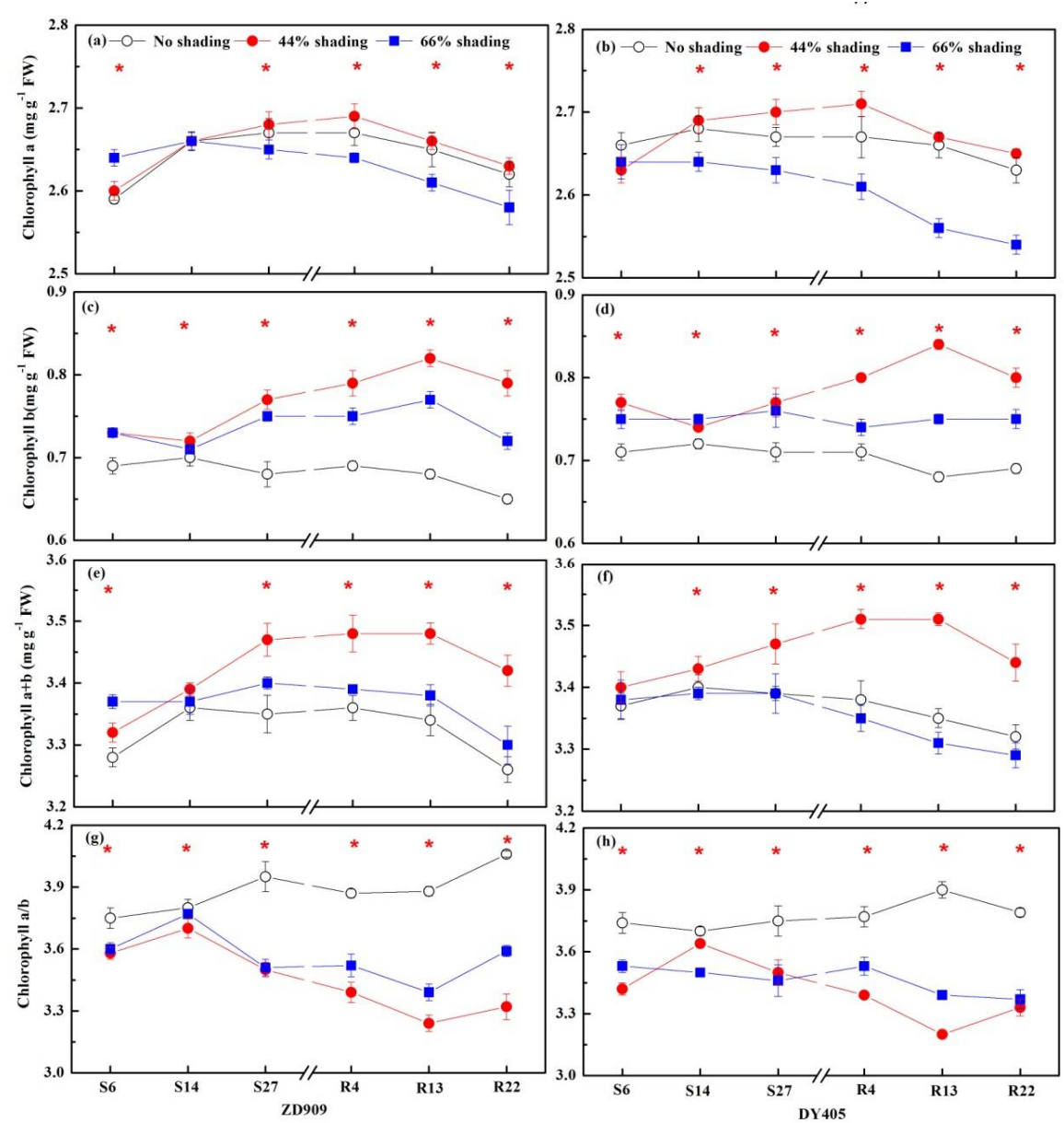

Fig. 1. Change in the content of chlorophyll in shading and light recovery treatments for maize in the spike stage. 
After shading, the chlorophyll $\mathrm{a} / \mathrm{b}$ values of the cultivars were lower than that of the control (Fig. 1g, h), and the chlorophyll a/b value of the ZD909 of 44\% shading treatment was the lowest, whereas the chlorophyll a/b value was the same for DY405 in the $66 \%$ shading treatment. After light recovery, the chlorophyll $\mathrm{a} / \mathrm{b}$ values of the cultivars were the lowest in the $44 \%$ shading treatment, followed by the $66 \%$ shading treatment and the highest in the control treatment.

In the spike stage, the initial fluorescence of both the cultivars increased with the increase of shade degree (Fig. 2 a, b), which was maximum on day 19 after shading. The ZD909 in the 66\% shading treatment had substantial differences compared with the control, whereas fluorescence in all three treatments of DY405 differed greatly. In ZD909, the effect of the 44\% shading treatment was relatively small; differences among the shading treatments for ZD909 were not significant.

The PSII photochemical efficiency $(\mathrm{Fv} / \mathrm{Fm})$ of two cultivars of $44 \%$ shading treatment increased whereas it decreased in the $66 \%$ shading treatment (Fig. 2c, d). The PSII actual photochemical efficiency (f PSII) of the two cultivars decreased with the increase in shading and light recovery (Fig. 2e, f). Differences between the shading treatments and the control were found on days 14 and 19 after shading. Shading and light recovery all lead to the reduction of electron transfer efficiency (ETR) (Fig. 2g, h) and thus this value reduced significantly with increased degree of shading.
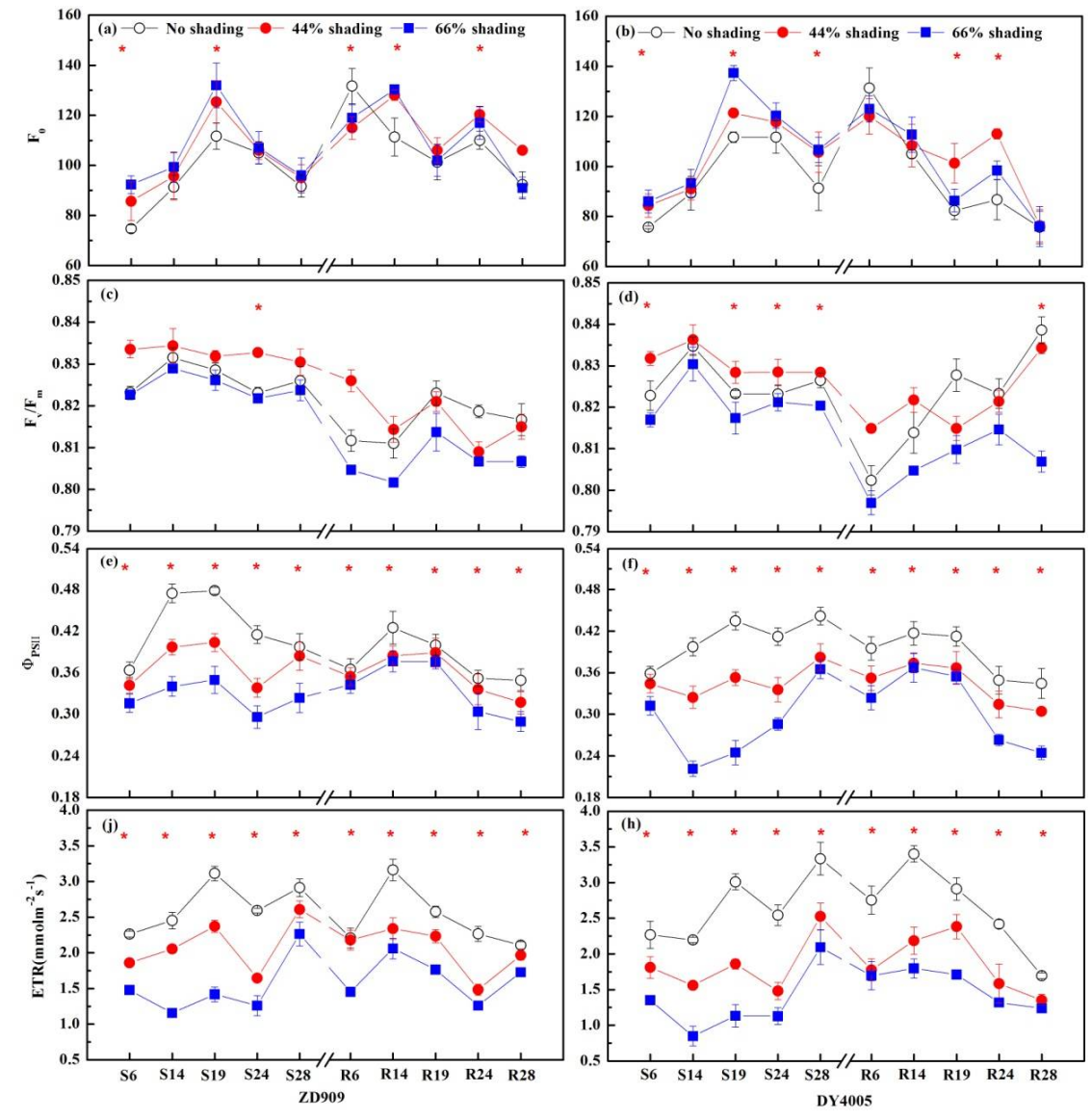

Fig. 2. Dynamic change in chlorophyll fluorescence parameters of shading and light recovery in spike stage. 
The experimental results showed that the content of chlorophyll a in the $44 \%$ shading increased whereas it decreased in the $66 \%$ shading. The degree of increase in the content of chlorophyll $b$ in the density-tolerant maize cultivar ZD909 was higher than the increase found in the density-intolerant maize cultivar DY405. Higher chlorophyll content is beneficial to the accumulation of photosynthetic products and differs from the linear reduction in chlorophyll content was observed with, the increase in the degree of shading (Mauro et al. 2011). Cultivar ZD909 maintained a high level of the depleting pigment (chlorophyll b) by decreasing the value of chlorophyll $\mathrm{a} / \mathrm{b}$; when light was insufficient, it regulated the content of pigments dynamically to adapt to different light conditions and thus improve its ability to capture light energy.
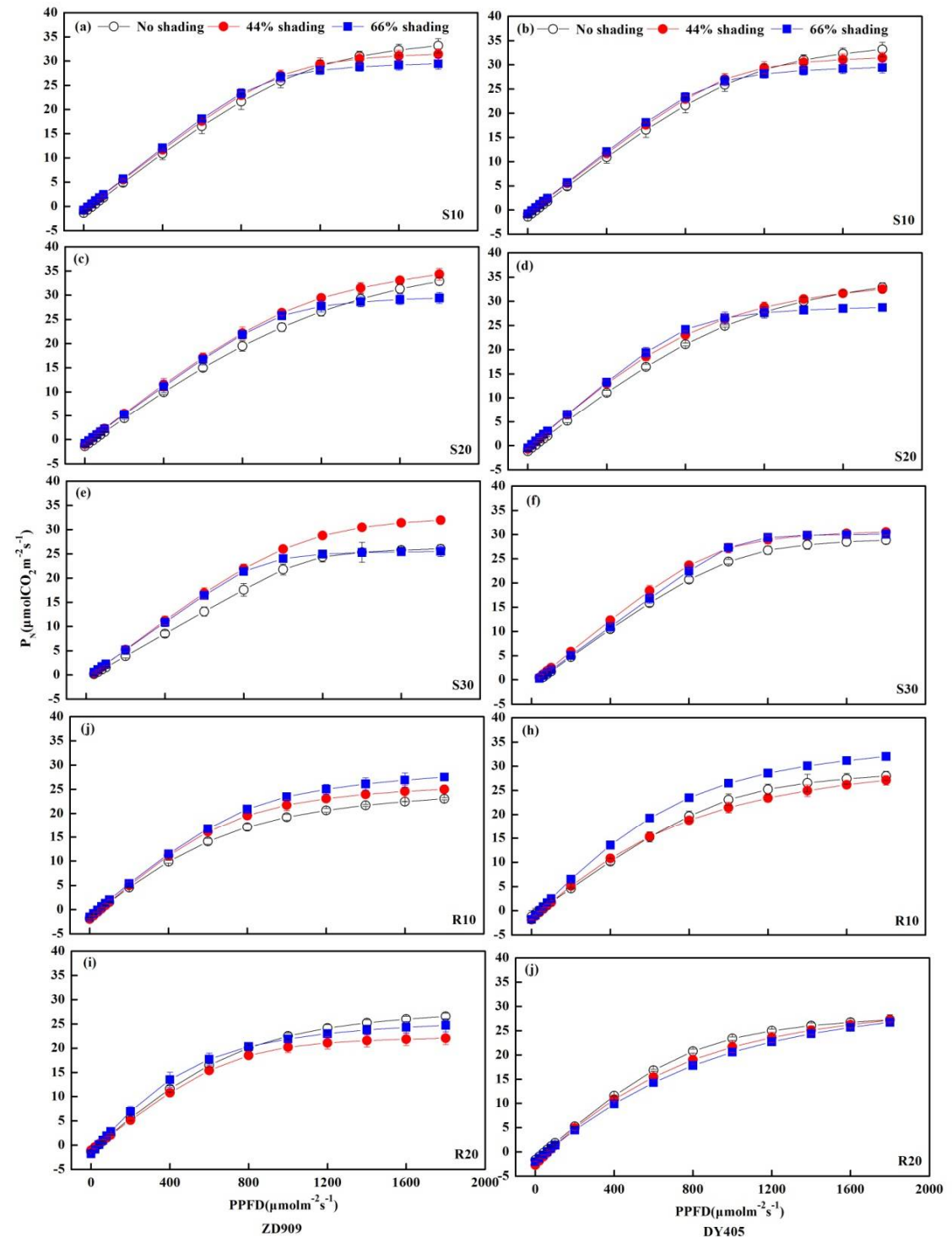

Fig .3. Dynamic change of light-response curve of shading and light recovery in the spike stage of maize. 
Analysis of chlorophyll fluorescence is the most widely used technology to monitor plant photosynthesis because it is convenient, highly sensitive and does not damage the plant (among other characteristics). Chlorophyll fluorescence can accurately reflect changes in photosynthesis under shade conditions (Dai et al. 2009, Rascher et al. 2000). An increase in $\mathrm{F}_{0}$ indicates that the PSII reaction center is damaged; it is measured when all the reaction centers are open and the plastoquinone is fully oxidized. This study showed that the $\mathrm{F}_{0}$ increased with the increase in degree of shade during the spike stage. Values indicated that the leaf thylakoid membrane was damaged, which caused the damage of the PSII reaction center, DY405 had a greater decrease than ZD909, which illustrated that leaves of DY405 obtained less light energy and the photosynthetic electron transport was blocked under shade conditions, leading to a decline in $\Phi$ n line g to light reduction in the ratio of light energy absorbed by leaves used for photosynthetic electron transport. The value of maximal photochemical efficiency (Fv/Fm) is close to 0.83 under no stress (Kalaji et al. 2012). The value of $\mathrm{Fv} / \mathrm{Fm}$ of this test was between 0.79 and 0.84 , which showed that the leaves in the $44 \%$ shading treatment still had higher light energy conversion efficiency, which suggests that shade can increase the potential of PSII photochemical to improve the utilization rate of light energy and thus compensate the influence of weak light on photosynthesis - a reaction mechanism to adapt to weak light stress as reported by Li et al. (2005) and Mu et al. (2008), Mauro et al. (2011). In contrast, the $\mathrm{Fv} / \mathrm{Fm}$ in the $66 \%$ shading treatment decreased. This decrease may be caused by the shade tolerance of different cultivars and different shade durations; the Fv/Fm of both the maize cultivars after illumination recovery was lower in the high-shade treatments. The reduction in the $\mathrm{Fv} / \mathrm{Fm}$ of DY405 in the $66 \%$ shading treatment was higher later in illumination recovery, which indicated that the high degree of shade resulted in a lower energy potential in PSII, a decrease in PSII potential activity and photochemical efficiency, and lower efficiency in the PSII light energy conversion, ultimately resulting in a negative effect on photosynthesis.

When the photosynthetic active radiation was in $0-200 \mu \mathrm{mol} / \mathrm{m}^{2} / \mathrm{s}$, the net photosynthetic rate of each treatment took on linear increase trend with the increase of the photosynthetic active radiation and then flattened. The density-tolerant and density-intolerant maize cultivars differed in their responses to changes in light intensity after shading treatment and light recovery. During the shade treatments, the dark respiration rate of the density-intolerant maize cultivar decreased slightly than that of the density-tolerant maize cultivar. Compared with the density-tolerant maize cultivar, the dark respiration rate of the density-intolerant maize cultivar increased highly; in the $44 \%$ shading and $66 \%$ shading treatments respiration rates were 90.20 and $88.24 \%$ higher than that of the control treatment (Fig. 3). The change in dark respiration rate in the density-tolerant maize cultivar was not substantial.

\section{Acknowledgments}

This research was supported by the National Key Research and Development Program of China 2016YDF0300103 2016YDF0300801 2017YFD0300703.

\section{References}

Arnon DI 1949. Copper enzymes in isolated chloroplasts: polyphenoloxidase in Beta vulgaris. Plant Physiol. 24(1): 1-15.

Bell GE, Danneberger TK and Mcmahon MJ 2000. Spectral irradiance available for turfgrass growth in sun and shade. Crop Sci. 40(1): 189-195.

Craine JM and Reich PB 2005. Leaf-level light compensation points in shade-tolerant woody seedlings. New Phytologist 166(3): 710-713. 
Dai Y, Shen Z, Liu Y, Wang LL, David H and Lu HF 2009. Effects of shade treatments on the photosynthetic capacity, chlorophyll fluorescence, and chlorophyll content of Tetrastigma hemsleyanum Diels et Gilg. Environmental \& Experimental Bot. 65(2): 177-182.

Du CF, Li CH, Liu T and Zhao YL 2011. Response of anatomical structure and photosynthetic characteristics to low light stress in leaves of different maize genotypes. Acta Ecologica Sinica 31(21): 6633-6640.

Feng YL, Cao KF and Zhang JL 2004. Photosynthetic characteristics, dark respiration, and leaf mass per unit area in seedlings of four tropical tree species grown under three irradiances. Photosynthetica 42(3): 431-437.

Jiang H, Wang XH, Deng QY, Yuan LP and Xu DQ 2002. Comparison of some photosynthetic characters between two hybrid rice combinations differing in yield potential. Photosynthetica 40(1): 133-137.

Joesting HM, Mccarthy BC and Brown KJ 2009. Determining the shade tolerance of American chestnut using morphological and physiological leaf parameters. Forest Ecology \& Management 257(1): 280-286.

Kalaji HM, Goltsev V, Bosa K, Allakhverdiev SI, Strasser RJ and Govindjee 2012. Experimental in vivo measurements of light emission in plants: a perspective dedicated to David Walker. Photosynthesis Research 114(2): 69-96.

Liang KM, Lin ZF, Ren H, Liu N, Zhang QM, Wang J, Wang J and Guan LL 2010. Characteristics of sun- and shade-adapted populations of an endangered plant Primulina tabacum Hance. Photosynthetica 48(4): 494-506.

Lichtenthaler HK 1988. In vivo chlorophyll fluorescence as a tool for stress detection in plants: Springer Netherlands. Germany. pp.129-142.

Li C, Luan L, Wang Q, Li N and Zhao YL 2005. Effects of seedling shading and light intensity transfer on photosynthetic efficiency of different maize (Zea mays L.) hybrids. Acta Agronomica Sinica 31(3):381-385.

Li PM, Cai RG, Gao HY, Peng T and Wang ZL 2007. Partitioning of excitation energy in two wheat cultivars with different grain protein contents grown under three nitrogen applications in the field. Physiologia Plantarum 129(4): 822-829.

Lv JH, Wang X, Feng YM, Li YF, Zhao HX and Wang Y 2012. Effects of shading on the photosynthetic characteristics and anatomical structure of Trollius chinensis Bunge. Acta Ecologica Sinica 32(19): 6033-6043.

Mauro RP, Occhipinti A, Longo AMG and Mauromicale G 2011. Effects of shading on chlorophyll content, chlorophyll fluorescence and photosynthesis of subterranean clover. Journal of Agronomy \& Crop Science 197(1): 57-66.

Mu H, Jiang D, Wollenweber B, Dai T, Jing Q and Cao W 2010 Long-term low radiation decreases leaf photosynthesis, photochemical efficiency and grain yield in winter wheat. J. Agron. Crop Sci. 196(1): $38-47$.

Mu HR, Jiang D, Dai TB, Jing Q and Cao WX 2008. Effect of shading on photosynthesis and chlorophyll fluorescence characters in wheat flag leaves. Scientia Agricultura Sinica 41(2): 599-606.

Olaf VK and Snel JF 1990. The use of chlorophyll fluorescence nomenclature in plant stress physiology. Photosynthesis Research 25: 147-150.

Pires MV, Almeida AAF, Figueiredo AL, Gomes EP and Souza MM 2011. Photosynthetic characteristics of ornamental passion flowers grown under different light intensities. Photosynthetica 49: 593-602.

Praba ML, Vanangamudi M, Thandapani V 2004. Effects of low light on yield and physiological attributes of rice. International Rice Research Institute Repository. Manila, Philippines

Rascher U, Liebig M and Luttge U 2000. Evaluation of instant light-response curves of chlorophyll fluorescence parameters obtained with a portable chlorophyll fluorometer on site in the field. Plant Cell \& Environ. 23(12): 1397-1405.

Rozendaal DMA, Hurtado VH and Poorter L 2006. Plasticity in leaf traits of 38 tropical tree species in response to light; relationships with light demand and adult stature. Functional Ecology 20: 207-216.

Singh VP, Dey SK and Murty KS 1988. Effect of low light stress on growth and yield of rice. Indian J. Plant Physiol. 31(1): 84-91. 
Viji MM, Thangaraj M and Jayapragasam M 1997. Effect of low light on photosynthetic pigments, photochemical efficiency and hill reaction in rice (Oryza sativa L.). J. Agron. Crop Sci. 178(4): 193-196.

Wang K, Zhu JJ, Yu LZ, Sun YR and Chen GH 2009. Effects of shading on the photosynthetic characteristics and light use efficiency of seedlings. Chinese J. Plant Ecol. 33(5):1003-1012.

Wang L, Deng F and Ren WJ 2015. Shading tolerance in rice is related to better light harvesting and use efficiency and grain filling rate during grain filling period. Field Crops Res. 180: 54-62.

Zhang CJ, Chu HJ, Chen GX, Shi DW, Zuo M, Wang J, Lu CG, Wang P and Chen L 2007. Photosynthetic and biochemical activities in flag leaves of a newly developed superhigh-yield hybrid rice (Oryza sativa) and its parents during the reproductive stage. J. Plant Res. 120(2): 209-217.

(Manuscript received on 5 March, 2018; revised on 9 January, 2019) 